\title{
Study on Critical Success Factors Estimation in IT System Development
}

\author{
Shinobu Komaia, Hamdani Saidib*, Hiroshi Nakanishia \\ a Malaysia-Japan International Institute of Technology, Universiti Teknologi Malaysia, 54100 Kuala Lumpur, Malaysia \\ ${ }^{b}$ Business Development, Universiti Teknologi Malaysia, 54100 Kuala Lumpur, Malaysia \\ *Corresponding author: hamdani.kl@utm.my
}

\begin{abstract}
The success of IT system development largely depends on the System Requirements Definition (SRD) phase. Researches on Critical Success Factors (CSFs) in the SRD phase are very few. This paper aims to make clear the CSFs in the SRD phase of IT system development. To achieve this, first, interviews to discover "difficult items" in the SRD phase were executed to participants who were engaged in three highly advanced IT system developments. Second, major difficult items were extracted from the interview results. Third, CSFs estimation was executed from the extracted major difficult items. Then, the estimated CSFs were compared to those obtained from the interviews. As a result, CSFs were found to be almost the same between those estimated and interviewed. Through this research, it can be concluded that 1) Customer/User Involvement, 2) Clear project goals, and 3) Technical skills of the project team are the major CSFs in the SRD phase.
\end{abstract}

Keywords: IT system; critical success factors; system requirements definition; system development

(C) 2017 Penerbit UTM Press. All rights reserved

\subsection{INTRODUCTION}

It is well-known that IT system development success largely depends both on the clearness of the ordering side system requirements and on the trustee side skillfulness of making the system requirement definition [1], [2]. There are many reports on system development delay due to long times to complete system requirement definitions [3], [4]. However, there are no reports which analyses the causes of time losses in system requirement definitions. Time losses are thought to originate both in the ordering side and trustee side. Unclearness of the system requirements of an ordering side is one of the causes of time delay. Lack of trustee side skills is another cause of time delay, for example, the skills to use the most advanced package software required by the ordering side. One of the best ways to make clear the cause of time losses is to interview about difficult items, problems and their solutions to the engineers who have experience being engaged in the SRD phase. The solution for each of the difficult items and problems will lead to the CSFs. About the IT system development, the Standish CHAOS Report from 1994 has illustrated that top 10 factors found in successful projects [5]. There are many researches for Critical Success Factors (CSFs) in IT fields [6], [7], [8]. However, Researches on Critical Success Factors (CSFs) in the SRD phase are very few. This paper aims to make clear the CSFs in the SRD phase of IT system development through interviews to engineers who were engaged in three different kinds of advanced IT system developments.

\subsection{RESEARCH METHODOLOGY}

To make CSFs in the SRD phase clear, the research was conducted as in the following:

1) To know the difficult items, interviews were executed to the engineers who were engaged in the SRD phase of the three systems whose characteristics are shown in Table 1.

2) Major difficult items were extracted from the difficult items. Through analysing the difficult items, the CSFs were estimated.

Table 1 Targeted three system characteristics

\begin{tabular}{|c|c|c|c|}
\hline Items & System 1 & System 2 & System 3 \\
\hline 1. Number of functions to be realized (small, medium, large) & Small & Medium & Large \\
\hline 2. Degree of the processing function complexity (small, medium, large) & Small & Medium & Large \\
\hline 3. Mutual dependence between the processing functions (small, medium, large) & Small & Medium & Large \\
\hline 4. Use of the latest middleware (Yes, No) & Yes & Yes & Yes \\
\hline 5. Cooperation with external systems (Yes, No) & Yes & Yes & Yes \\
\hline 6. Number of user interface screens (small, medium, large) & Small & Medium & Large \\
\hline 7. Number of user input items (small, medium, large) & Small & Medium & Large \\
\hline 8. Processing function change corresponding to the user inputs (small, medium, large) & Small & Medium & Large \\
\hline 9. System development size (Man-Month) & $21 \mathrm{MM}$ & $63 \mathrm{MM}$ & $566 \mathrm{MM}$ \\
\hline
\end{tabular}




\subsection{RESEARCH RESULTS}

\section{Design of Interview Items}

The interviewees were engineers who were engaged in the development of the three systems shown in Table 1 . The question items were designed from the viewpoint that elicits the difficult items in the SRD for the three systems. Also, they were designed so that an estimation of the CSFs became easy from the analysis of the answers obtained from the interview.

1) Did the ordering side have clear requirements for the development system?

If they did not, what did you do?

2) How well is the support from the top management of the trustee side?

If you were not supported or were not supported enough, what did you do?

3) What difficulties did you encounter during the SRD phase?

When did you encounter the difficulties? What is your solution for the difficulties?

4) Did the trustee side engineers have enough skills or experiences for SRD?

If they did not, how did you overcome it?

5) Was it necessary to ask for help from cooperating companies and consultants outside of the company?

In what kind of situation was it necessary, and how was the result?

6) Was it necessary for you to evaluate the middleware software which the ordering side requested to use?

If it was necessary, why was it necessary to evaluate it from the trustee side and what was the evaluation result?

\section{Design of Critical Success Factors}

The CSFs were designed by referring to the CSFs proposed by the papers of Bradley [9] and Imtiaz et al. [10] as shown in Table 2. In the two papers, 15 CSFs were proposed by Bradley including 10 CSFs proposed by Imtiaz. So, new CSFs in the SRD phase were designed which consist of 15 CSFs proposed by Bradley and 5 CSFs proposed by Imtiaz et al.

New CSFs were designed in such a way that they cover a wide range of system types.

Table 2 Design of critical success factors in SRD Phase

\begin{tabular}{|c|c|c|}
\hline \# & Critical Success factors & Meaning \\
\hline 1 & Detailed formal plan with well- defined tasks & $\begin{array}{l}\text { There should be project management planning of well-defined tasks and } \\
\text { accurate estimation of required effort [11]. }\end{array}$ \\
\hline 2 & Clear project goals & $\begin{array}{l}\text { Ding et al. (2008) noted that the goals are set in accordance with the } \\
\text { requirements of the customer [12]. }\end{array}$ \\
\hline 3 & Time budget, manageable workload & $\begin{array}{l}\text { Reasonable distribution of workload on the staff of coordination is very high } \\
\text { artistic work [13]. }\end{array}$ \\
\hline 4 & Analysts with knowledge of both business and technology & $\begin{array}{l}\text { Obtain "business" analysts. One of the critical workforce requirements for } \\
\text { the project was the ability to obtain analysts with both "business" and } \\
\text { technology knowledge [14]. }\end{array}$ \\
\hline 5 & Technical skills of project team & $\begin{array}{l}\text { They possess the necessary technical skills and have adequate technology to } \\
\text { perform their tasks }[15] \text {. }\end{array}$ \\
\hline 6 & Selection and management of consultants and staff & $\begin{array}{l}\text { Reel (1999) noted that building the right team means getting suitable people } \\
\text { in the team. Well organized team would be doing good job which outcome } \\
\text { the good result [16]. }\end{array}$ \\
\hline 7 & Third parties fill gaps in expertise and transfer knowledge & $\begin{array}{l}\text { Howells (2006) referred that actors (third party) fill gaps in information and } \\
\text { knowledge in industrial networks [17]. }\end{array}$ \\
\hline 8 & Problem solving with vendors & $\begin{array}{l}\text { They had IT personnel with knowledge and experience performed better in } \\
\text { problem solving than a project group without them [18]. }\end{array}$ \\
\hline 9 & Top management support & $\begin{array}{l}\text { Fortune \& White (2006) referred that this factor can be affected by the } \\
\text { general state of the economy; a lack of this factor can lead to project failure } \\
\text { [19]. }\end{array}$ \\
\hline 10 & Top management is engaged, not just involved & $\begin{array}{l}\text { Brown et al. identified this CSF is the first of five factors in ERP } \\
\text { implementation project [20] }\end{array}$ \\
\hline 11 & Management communication, education and expectations & $\begin{array}{l}\text { Expectations at every level need to be communicated. Management of } \\
\text { communication, education and expectations are critical throughout the } \\
\text { organization [11] }\end{array}$ \\
\hline 12 & Establishment of trouble shooting mechanism & $\begin{array}{l}\text { Trouble shooting is an important independent variable and project success } \\
\text { categorized by project phase [21]. }\end{array}$ \\
\hline 13 & Change management hand in hand with project management & $\begin{array}{l}\text { Brown et al. identified this CSF is the fourth of five factors in ERP } \\
\text { implementation project [20]. }\end{array}$ \\
\hline 14 & Monitoring and feedback against initial plan & $\begin{array}{l}\text { Adequate monitoring and control is important for the quality of the project } \\
\text { [19]. }\end{array}$ \\
\hline 15 & Redesign of business processes & $\begin{array}{l}\text { Many companies "go to war" with the package and try to make it meet their } \\
\text { process requirements [14] }\end{array}$ \\
\hline 16 & Leadership & $\begin{array}{l}\text { Many research studies have discussed the importance and/or style of project } \\
\text { leadership [22] } \\
\text { Leaders should have strong technical and relational skills [23]. }\end{array}$ \\
\hline 17 & Team Work & $\begin{array}{l}\text { Cross-functional team and cooperation between members of team and team } \\
\text { work was described as a CSF for IT projects [24]. }\end{array}$ \\
\hline
\end{tabular}




\begin{tabular}{|c|l|l|}
\hline 18 & Customer/User Involvement & $\begin{array}{l}\text { Park et al. (2011) identified Customer/user involvement in application design } \\
\text { is necessary and the lack of it can result in IS project failure [25]. }\end{array}$ \\
\hline 19 & Risk Management & $\begin{array}{l}\text { Fortune \& White (2006) also referred that In a successful projects risk } \\
\text { analysis was done at the start of the project and risks that arose were handled } \\
\text { successfully, whereas in the failed project no risk analysis was done [19]. }\end{array}$ \\
\hline 20 & Adequate Requirement & $\begin{array}{l}\text { Ding et al. (2008) also studied this factor that although difficult to gather is } \\
\text { very important for the success of the system; inadequate requirements usually } \\
\text { lead to a failed project. [12]. }\end{array}$ \\
\hline
\end{tabular}

Extraction of Major Difficult Items from the Interview Results

Two engineers of the leader and the sub-leader of the SRD for each of the three IT systems were interviewed. They were selected as the best engineers as they knew all the progress and problems of the SRD. Through the interviews, many difficult items and solutions were answered as shown in Appendix A. Major difficult items were extracted from the difficult items answered by removing the less important answers. They are shown in Table 3.

Table 3 Major difficult items obtained by interviews

\begin{tabular}{|l|l|}
\hline System \# & Major difficult items \\
\hline 1 & 1) Insufficiency of knowledge about the middleware which the ordering side required to use \\
\hline 2 & 1) Insufficient information about the system requirements from the ordering side \\
\cline { 2 - 3 } & 2) Insufficiency of knowledge about the middleware which the ordering side required to use \\
\cline { 2 - 3 } & 3) Lack of project management \\
\cline { 2 - 3 } & 4) Difficulty in direct communication with the ordering side \\
\hline \multirow{5}{*}{3} & 1) Insufficiency of knowledge about the middleware which the ordering side required to use \\
\cline { 2 - 3 } & 2) Insufficient information about the system requirements from the ordering side \\
\cline { 2 - 3 } & 3) Engineer skills mismatching for the SRD phase \\
\cline { 2 - 3 } & 4) Difficulty in direct communication with the ordering sides \\
\cline { 2 - 2 } & 5) Lack of cooperation with the ordering side \\
\cline { 2 - 2 } & $\begin{array}{l}\text { 6) Lack of methodology for the current system development with the ordering side and partner System } \\
\text { Integrator. }\end{array}$ \\
\hline
\end{tabular}

Estimation of CSFs from the Major Difficult Items

The CSFs for each of the three systems were estimated from the extracted major difficult items via the possible solutions as in the following:

CSFs Estimated for System 1:

\section{1) CSF-5: Technical Skills of Project Team and CSF-7: Third parties fill gaps in expertise and transfer knowledge}

The major difficult item is "Insufficiency of knowledge about the middleware which the ordering side was required to use". The possible solutions for this are to add engineers with sufficient knowledge and to assign the third party engineers filling the knowledge gap about the middleware. Thus, the CSF is estimated to be "Technical skills of project team" and "Third parties fill gaps in expertise and transfer knowledge".

\section{CSFs Estimated for System 2:}

\section{1) CSF-2: Clear Project Goals and CSF-18: Customer/User Involvement}

The first of the major difficult items is "Insufficient information about the system requirements from the ordering side". This results in a long period to complete SRD, which causes developmental delay. This can be solved only by the ordering side. The possible solutions for this are to request the customer more involvement and to ask the partner System Integrator to jointly get the ordering side requirements. Thus, the CSF is estimated to be "Clear project goals" and "Customer/User involvement".

\section{2) CSF-5: Technical Skills of Project Team and CSF-7: Third parties fill gaps in expertise and transfer knowledge}

The second of the major difficult item is "Insufficiency of knowledge about the middleware which the ordering side was required to use". The possible solutions for this are to add engineers with sufficient knowledge and to assign the third party engineers filling the knowledge gap about the middleware. Thus, the CSF is estimated to be "Technical skills of project team" and "Third parties fill gaps in expertise and transfer knowledge".

\section{3) Detailed formal plan with well- defined tasks and Monitoring and Feedback Against the Initial Plan}

The third of the major difficult items is "Lack of project management". This refers to changes such as the project formation change from the initial cause development delay. The possible solution for this is to replace the project manager. Thus, the CSF is estimated to be "Detailed formal plan with well-defined tasks" and "Monitoring and feedback against the initial plan". 


\section{4) CSF-18: Customer/User Involvement}

The fourth of the major difficult items is "Difficulty of indirect communication with the ordering sides". This arises so often from the multi-layered development project formation on the trustee side. In this case, the interviewee was engaged in the SRD under the control of a prime contractor. The possible solution for this is to remove the intermediary. This means customer involvement directly. Thus, the CSF is estimated to be "Customer/User involvement".

CSFs Estimated for System 3:

1) CSF-5: Technical Skills of Project Team, CSF-7: Third parties fill gaps in expertise and transfer knowledge, and CSF-11: Management communication, education and expectations

The first of the major difficult items is "Insufficient knowledge about the middleware which the ordering side is required to use". The possible solutions for this are to add engineers with sufficient knowledge, to assign the third party engineers filling the knowledge gap about the middleware, and to make the training fulfilling the knowledge. Thus, the CSF is estimated to be "Technical skills of project team", "Third parties fill gaps in expertise and transfer knowledge", and "Management communication, education and expectations".

\section{2) CSF-2: Clear Project Goals and CSF-18: Customer/User Involvement}

The second of the major difficult items is "Insufficient information about the system requirements from the ordering side". The possible solutions for this are to request the determination of the requirements by the additional staff, to request the customer more involvement, and to ask the partner System Integrator to jointly get the ordering side requirements. Thus, CSF is estimated to be "Clear project goals" and "Customer/User involvement".

3) CSF-5: Technical Skill of Project Team, CSF-7: Third parties fill gaps in expertise and transfer knowledge, and CSF-11: Management communication, education and expectations

The third of the major difficult items is "Engineer skills mismatching the SRD phase". In case the engineering skills do not match the ordering side requirements, it took a long time to complete the system requirement phase. The possible solutions for this are to add engineers with sufficient knowledge, to assign the third party engineers filling the knowledge gap about the middleware and to make the training fulfilling the knowledge. Thus, the CSF is estimated to be "Technical skills of project team", "Third parties fill gaps in expertise and transfer knowledge", and "Management communication, education and expectations".

4) CSF-18: Customer/User Involvement

The fourth of the major difficult items is "Difficulty in direct communication with the ordering sides". The possible solution for this is to have direct communication with the ordering side. This means more customer involvement directly. Thus, the CSF is estimated to be "Customer/User involvement".

\section{5) CSF-2: Clear Project Goals and CSF-18: Customer/User Involvement}

The fifth of the major difficult items is "Lack of cooperation with the ordering side". While the ordering side required the project to get the ordering side's requirements from the document of the existing system, it took long time to complete the SRD phase without cooperation from the ordering side. The possible solution for this is to request the ordering side to replace the system. This means more customer cooperation and involvement. Thus, the CSF is estimated to be "Clear project goals" and "Customer/User involvement".

\section{6) CSF-2: Clear Project Goals, and CSF-18: Customer/User Involvement}

The sixth of the major difficult items is "Lack of methodology for the current system development". While the ordering side and partner System Integrator required to use the middleware, it took long time to complete the SRD phase without appropriate development methodology, such as concurrent engineering, developing the system design and programing at the same time. The possible solution for this is to take the concurrent engineering, developing the system design and programing at the same time. This means to be needed clear Project goal and more customer cooperation and involvement. Thus, the CSF is estimated to be "Clear project goals", and "Customer/User involvement".

Table 4 shows the Critical Success Factors estimation results from the major difficult items via the possible solutions. 
Table 4 Critical success factors estimated from the major difficult items via the possible solutions

\begin{tabular}{|c|c|c|c|}
\hline $\begin{array}{r}\text { System } \\
\#\end{array}$ & Major difficult Items & Possible solutions & Estimated CSFs \\
\hline 1 & $\begin{array}{l}\text { 1) Insufficiency of knowledge about the } \\
\text { middleware which the ordering side is } \\
\text { required to use }\end{array}$ & $\begin{array}{l}\text { - To add engineers with sufficient knowledge } \\
\text { - To assign the third party engineers filling the } \\
\text { knowledge gap about the middleware }\end{array}$ & $\begin{array}{l}\text { CSF-5: Technical skills of project team } \\
\text { CSF-7: Third parties fill gaps in expertise } \\
\text { and transfer knowledge }\end{array}$ \\
\hline \multirow[t]{4}{*}{2} & $\begin{array}{l}\text { 1) Insufficient information about the } \\
\text { system requirements from the } \\
\text { ordering side }\end{array}$ & $\begin{array}{l}\text { To request the customer more involvement } \\
\text { - To ask the partner System Integrator to jointly } \\
\text { get the ordering side requirements }\end{array}$ & $\begin{array}{l}\text { CSF-2: Clear project goals } \\
\text { Customer/User involvement }\end{array}$ \\
\hline & $\begin{array}{l}\text { 2) Insufficiency of knowledge about the } \\
\text { middleware which the ordering side is } \\
\text { required to use }\end{array}$ & $\begin{array}{l}\text { To add engineers with sufficient knowledge } \\
\text { - To assign the third party engineers filling the } \\
\text { knowledge gap about the middleware }\end{array}$ & $\begin{array}{l}\text { CSF-5: Technical skills of project team } \\
\text { CSF-7: Third parties fill gaps in expertise } \\
\text { and transfer knowledge }\end{array}$ \\
\hline & 3) Lack of project management & - To replace the project manager & $\begin{array}{l}\text { CSF-1: Detailed formal plan with well- } \\
\text { defined tasks } \\
\text { CSF-14: Monitoring and feedback against } \\
\text { initial plan } \\
\end{array}$ \\
\hline & $\begin{array}{l}\text { 4) Difficulty in direct communication } \\
\text { with the ordering side }\end{array}$ & $\begin{array}{l}\text { - To remove the intermediary. This meant } \\
\text { customer involvement directly. }\end{array}$ & CSF-18: Customer/User involvement \\
\hline \multirow[t]{6}{*}{3} & $\begin{array}{l}\text { 1) Insufficiency of knowledge about the } \\
\text { middleware which the ordering side is } \\
\text { required to use }\end{array}$ & $\begin{array}{l}\text { To add engineers with sufficient knowledge } \\
\text { - To assign the third party engineers filling the } \\
\text { knowledge gap about the middleware. } \\
\text { - To make the training fulfilling the knowledge }\end{array}$ & $\begin{array}{l}\text { CSF-5: Technical skills of project team } \\
\text { CSF-7: Third parties fill gaps in expertise } \\
\text { and transfer knowledge } \\
\text { CSF-11: Management communication, } \\
\text { education and expectations }\end{array}$ \\
\hline & $\begin{array}{l}\text { 2) Insufficient information about the } \\
\text { system requirements from the } \\
\text { ordering side }\end{array}$ & $\begin{array}{l}\text { To request the determination of the } \\
\text { requirements by the additional staff } \\
\text { - To request the customer more involvement } \\
\text { - To ask the partner System Integrator to jointly } \\
\text { get the ordering side requirements }\end{array}$ & $\begin{array}{l}\text { CSF-2: Clear project goals } \\
\text { CSF-18: Customer/User involvement }\end{array}$ \\
\hline & $\begin{array}{l}\text { 3) Engineer skills mismatching for the } \\
\text { SRD phase }\end{array}$ & $\begin{array}{l}\text { To add engineers with sufficient knowledge } \\
\text { - To assign the third party engineers filling the } \\
\text { knowledge gap about the middleware. } \\
\text { - To make the training fulfilling the knowledge }\end{array}$ & $\begin{array}{l}\text { CSF-5: Technical skills of project team } \\
\text { CSF-7: Third parties fill gaps in expertise } \\
\text { and transfer knowledge } \\
\text { CSF-11: Management communication, } \\
\text { education and expectations } \\
\end{array}$ \\
\hline & $\begin{array}{l}\text { 4) Difficulty in direct communication } \\
\text { with the ordering sides }\end{array}$ & $\begin{array}{l}\text { To have direct communication with the } \\
\text { ordering side. This meant more customer } \\
\text { involvement directly. }\end{array}$ & Customer/User involvement \\
\hline & $\begin{array}{l}\text { 5) Lack of cooperation with the } \\
\text { ordering side }\end{array}$ & $\begin{array}{l}\text { - To request the ordering side to replace the } \\
\text { system. This meant more customer } \\
\text { cooperation and involvement. }\end{array}$ & $\begin{array}{l}\text { CSF-2: Clear project goals } \\
\text { CSF-18: Customer/User involvement }\end{array}$ \\
\hline & $\begin{array}{l}\text { 6) Lack of methodology for the current } \\
\text { system development. }\end{array}$ & $\begin{array}{l}\text { - To take the concurrent engineering, developing } \\
\text { the system design and programing at the same } \\
\text { time. This meant to be needed clear Project } \\
\text { goal and more customer cooperation and } \\
\text { involvement. }\end{array}$ & $\begin{array}{l}\text { CSF-2: Clear project goals } \\
\text { CSF-18: Customer/User involvement }\end{array}$ \\
\hline
\end{tabular}

\subsection{CONSIDERATIONS}

In this chapter, it is verified whether the estimation of the CSFs is correct or not. At the final stage of the interview, the engineering leaders were asked to select five CSFs from the 20 CSFs list shown in Table 2. Their selection results are shown at the right end of Table 5. Also, the estimated CSFs explained in the above section are shown in the middle section of Table 5. It can be understood that all the estimated CSFs are included in the selected CSFs. This means that the proposed estimation method by this paper is correct and useful. The reason why the CSFs are not perfectly the same as those of estimated and selected is thought to be the ambiguousness of the questions to the engineers who were interviewed. Some of the engineers who received interviews are supposed to answer the question from the general viewpoint of project management. 
Table 5 Estimated CSFs and their comparison with those of interviewed CSFs selected by the interviewee

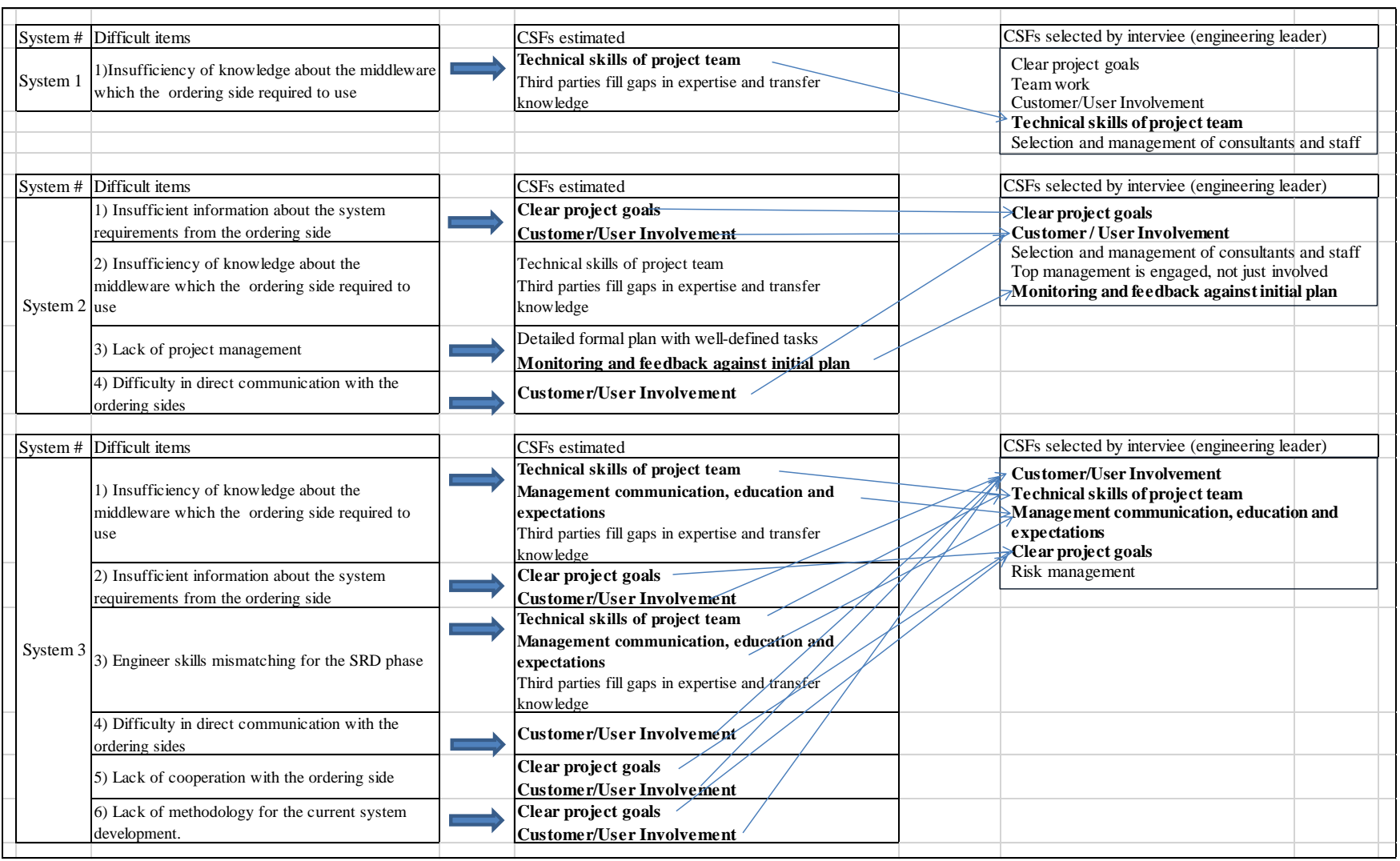

\subsection{CONCLUSION}

This paper aims to make clear the critical success factors (CSFs) in the system requirements definition (SRD). Through focusing on the consideration that CSFs are the solution for difficult items in an SRD process, a new method for the CSF estimation was studied from difficult items obtained by interviewing engineers who were engaged in SRD. This method is the syllogism which derives the possible solutions from the major difficulties and estimates CSFs based on the solutions.

As a result, the following conclusions were obtained:

1) To enable CSF estimation, appropriate interview items were designed in such a way that the engineers who were engaged in the SRD

were able to clearly point out difficult items.

2) Major difficulty items were extracted from the difficult items obtained from the interview.

3) Twenty CSFs were newly designed based on the CSFs proposed by the preceding study results.

4) To encounter the difficult items, the possible solutions were derived.

5) CSFs were estimated so that they solve the major difficult items extracted as described above.

6) The estimated CSFs were proven to be almost the same as those selected by the interviewee.

As described above, it can be concluded that the CSF estimation method proposed by this paper is correct and effective.

\section{References}

Anantatmula, V. S. (2008). The Role of Technology in the Project Manager Performance Model. Project Management Journal, 39(1), 34-48.

Belout, A., \& Gauvreau, C. (2004). Factors Influencing Project Success: The Impact of Human Resource Management. International Journal of Project Management, 22(1), 1-11.

Biehl, M. (2007). Success Factors for Implementing Global Information Systems. Communication of the ACM, 50(1), 52-58.

Bradley, J. (2008). Management Based Critical Success Factors in the Implementation of Enterprise Resource Planning systems. International Journal of Accounting Information Systems, 9(3), 175-200.

Brown, C. V., \& Vessey, I. (2003). Managing the Next Wave of Enterprise Systems: Leveraging Lessons from ERP. MIS Quarterly Executive, 2 (2003), $45-57$.

Ding, R. D. R., \& Wang, Y. W. Y. (2008). An Empirical Study on Critical Success Factors Based on Governance for IT Projects in China. 2008 4th International Conference on Wireless Communications, Networking and Mobile Computing, 1-7.

Doherty, M. J. (2011). Examining Project Manager Insights of Agile and Traditional Success Factors for Information Technology Projects: A Q-Methodology Study. Report submitted for the Project Management Institute, Marian University.

Fan, D. (2010). Analysis of Critical Success Factors in IT Project Management. Industrial and Information Systems (IIS), 20102 nd International Conference Proceeding Volume 2, 487-490.

Fortune, J., \& White, D. (2006). Framing of Project Critical Success Factors by a Systems Model. International Journal of Project Management, 24(1), 53-65.

Howells, J. (2006). Intermediation and the Role of Intermediaries in Innovation. Research Policy, 35(5), $715-728$.

Imtiaz, M. A., Al-Mudhary, A. S., Mirhashemi, M. T., \& Ibrahim, R. (2013). Critical Success Factors in Information Technology Projects. International Journal of Social, Human Science and Engineering, 7(12), 1913-1917. 
Ishii, N. (2006). A Project Management Framework at System Requirements Definition Phase. Bunkyo University, 47-66.

Khan, A. A., \& Keung, J. (2016). Systematic Review of Success Factors and Barriers for Software Process Improvement in Global Software Development. IET Software, $10(5), 125-135$.

McLeod, L., \& MacDonell, S. G. (2011). Factors That Affect Software Systems Development Project Outcomes. ACM Computing Surveys, 43(4), 1-56.

Mitani, Y., Matsumura, T., \& Barker, M. (2008). An Empirical Study of Process and Product Metrics based on In-process Measurements of a Standardized Requirements Definition Phase. Software Process and Product Measurement, 4895, 46-59.

Nah, F. F., \& Lau, J. L. (2001). Critical Factors for Successful Implementation of Enterprise Systems, Business Process Management Journal, 7(3), $285-296$.

Nikkei. (2013). Suruga bank IBM Trial Appeal, Compensation Instruction of About 42 Billion Yen to IBM Japan. Retrieved from http://www.nikkei.com/article/DGXNASFK2603G_W3A920C1000000/

Nikkei-ITpro. (2012). 5.5 Billion Yen in Vain, Failure of the Patent Office. Retrieved from http://itpro.nikkeibp.co.jp/article/COLUMN/20121204/441882/.

Park, J. Y., Im, K. S., \& Kim, J. S. (2011). The Role of IT Human Capability in the Knowledge Transfer Process in IT Outsourcing Context. Information \& Management, 48(1), 53-61.

Pinto, J., \& Slevin, D. (1987). Critical Factors in Successful Project Implementation. Engineering Management, 34(I), 22-27.

Reel, J. S. (1999). Critical Success Factors in Software Projects. IEEE Software, 16(3), 18-23.

Salmeron, J. L., \& Herrero, I. (2005). An AHP-based Methodology to Rank Critical Success Factors of Executive Information Systems. Computer Standards and Interfaces, 28(1), 1-12.

Sudhakar, G. P. (2012). A Model of Critical Success Factors for Software Projects. Journal of Enterprise Information Management, 25(6), 537-558.

Sumner, M. (1999). Critical Success Factors in Enterprise Wide Information Management Systems Projects. Proceedings of the 1999 ACM SIGCPR Conference, 297303.

The Standish Group. (2014). The Standish Group Report CHAOS. 


\section{Appendix}

Table A Answers Of The Interviewee And The Solutions

\begin{tabular}{|c|c|}
\hline System \# & Answers of the interviewee and the solution \\
\hline System 1 & $\begin{array}{l}\text { 1) There were no engineers in the SRD staff who had the experiences and knowledge about the use of the middleware requested by the } \\
\text { ordering side. The solution for this were (1) to add engineers with sufficient knowledge, (2) to assign the third party engineers filling } \\
\text { the knowledge gap about the middleware or (3) to make the training fulfilling the knowledge, *(3) This solution was not suitable since } \\
\text { the period of the project could not afford. }\end{array}$ \\
\hline System 2 & $\begin{array}{l}\text { 1) No clear system requirement was given by the ordering side. The solution for this were (1) to request the customer more involvement, } \\
\text { (2) to obtain business analysts, or (3) to ask the partner System Integrator to jointly get the ordering side requirements. *(2) This } \\
\text { solution was not suitable since the business analyst of this system is a few. } \\
\text { 2) There were no engineers in the SRD staff who had the experiences and knowledge about the use of middleware requested by the } \\
\text { ordering side. The solution for this were (1) to add engineers with sufficient knowledge, (2) to assign the third party engineers filling } \\
\text { the knowledge gap about the middleware, or (3) to make the training fulfilling the knowledge. *(3) This solution was not suitable } \\
\text { since the period of the project could not afford. } \\
\text { 3) The project manager was not properly assigned. The solution for this was to replace the project manager. } \\
\text { 4) Existence of a meaningless intermediary caused the worst communication between the ordering side and trustee side. The solution for } \\
\text { this was to remove the intermediary. This meant customer involvement directly. }\end{array}$ \\
\hline System 3 & $\begin{array}{l}\text { 1) There were very few engineers in the SRD staff who had the experiences and knowledge about the use of the middleware requested } \\
\text { by the ordering side. The solution for this were (1) to add engineers with sufficient knowledge, (2) to assign the third party engineers } \\
\text { filling the knowledge gap about the middleware, or (3) to make the training fulfilling the knowledge. *3) This solution was suitable } \\
\text { since the period of the project could afford. } \\
\text { 2) The ordering side did not determine the requirements. The solution for this were (1) to request the determination of the requirements } \\
\text { by the additional staff, (2) to request the customer more involvement, (3) to obtain business analysts, or (4) to ask the partner System } \\
\text { Integrator to jointly get the ordering side requirements. *(3) This solution was not suitable since the business analyst of this system is } \\
\text { a few. } \\
\text { 3) Engineers who had narrow experience about the use of middleware requested by the ordering side were assigned. The solution for this } \\
\text { were (1) to add engineers with sufficient knowledge, (2) to make the training fulfilling the knowledge, or (3) to assign the third party } \\
\text { engineers filling the knowledge gap about the middleware. *2) This solution was suitable since the period of the project could afford. } \\
\text { 4) The existence of a meaningless intermediary caused the worst communication between the ordering side and trustee side. The solution } \\
\text { for this was to have direct communication with the ordering side. This meant more customer involvement directly. } \\
\text { 5) It was supposedly good to recommend the replacement of the current system to a new infrastructure. The solution for this was to } \\
\text { request the ordering side to replace the system. This meant more customer cooperation and involvement. } \\
\text { 6) The partner System Integrator took eight months to become aware of the importance of the verification of the middleware which the } \\
\text { ordering side was required to use, resulting in a long delay of SRD. The solution for this was to take the concurrent engineering, } \\
\text { developing the system design and programing at the same time. This meant to be needed clear Project goal and more customer } \\
\text { cooperation and involvement. }\end{array}$ \\
\hline
\end{tabular}

